\title{
THE ROLE OF KNOWLEDGE MANAGEMENT AND THE MOVEMENT FROM EXPLICIT TO TACIT KNOWLEDGE, IN BRIDGING THE EARLY ADOPTION GAP IN TECHNOLOGY PRODUCT INTRODUCTION
}

\author{
Dominic Cincotta, Robert Morris University, Pittsburgh, Pennsylvania
}

\begin{abstract}
This paper explores how industries can understand and plan their communication and knowledge transfer process with consumers as products move along the adoption curve. The adoption curve is defined and each stage is clearly identified. How knowledge and consumers are moved through this curve is supported with reference to current literature. This movement is documented as a planned progression from an explicit cultural template to a tacit understanding. This move creates communities of understanding which draw new consumers in, facilitating a bridge in the adoption gap. A practical application of the phenomenon is shown through the use of Apple's iPod, highlighting the development of the " $i$ " culture. A strategic recommendation for enterprises planning to introduce new technology is offered as a conclusion to this paper.
\end{abstract}

Keywords: Adoption Curve, Technology, Adoption Gap, Knowledge Management, Explicit, Tacit,

\section{INTRODUCTION}

The concept of the adoption curve and the phenomenon of the adoption gap have been explored and explained through multiple veins of research. The origin of this theory is the diffusion process developed from agricultural studies. In the study of technology, this is known as the Technology Adoption Lifecycle. Published by Gross and Ryan $(1942,1943)$ and extended by Bohlen (1957), a phenomenon was eventually realized. These authors cited a gap between technology that was introduced and the disparity of this technology's acceptance versus rejection. This phenomenon is illustrated by a line graph showing a bell curve with a break early in the up slope.

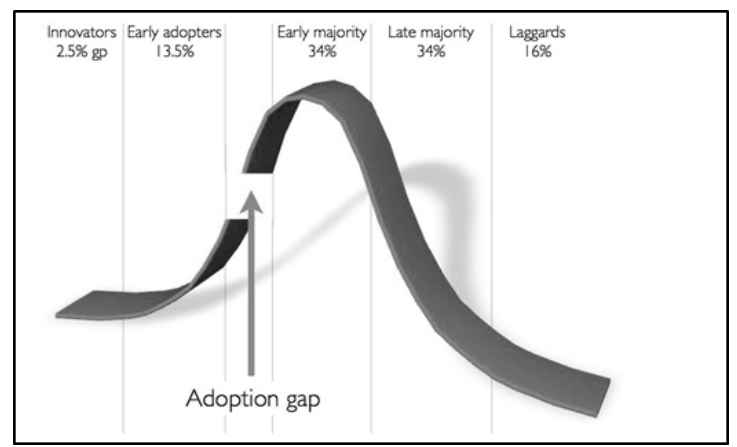

Figure 1- Adoption Curve

Innovators - Innovators suffer from little impact of marketing but give high credence to input from third parties (Menaker)

Early Adopters - Innovation gatekeepers - Knowledge community creators

Early Majority - First followers - knowledge community translators

Late Majority - Power Base - knowledge community participants

Laggard - aware and disrupters 


\section{Issues in Information Systems \\ Volume 15, Issue I, pp. 118-122, 2014}

This article explores an idea to be researched as to how industries can understand and plan their communication and knowledge transfer process with consumers as products move along this curve. A hypothesis is presented to be tested as to how the adoption gap can be bridged through the management of knowledge in the product lifecycle.

Researchers have identified at least five positions on the adoption curve: innovators, early adopters, early majority, late majority, and laggards. Innovators are the members of the group that introduces a new idea or product to the market. The early adopters are the first group to grasp onto this idea, understand how it works, and set the image for future success of a product or idea. The early majority is the group that, in leadership studies, is known as the first followers and the place where the early adopters and innovators gain the power to create a following. The early majority proliferates the symbols and signs generated by the early adopters. It is at this point that the early adopter's knowledge base moves from explicit to tacit. There is a gap that must be bridged between the early adopters and the early majority which accelerates the adoption achieving acceptable market saturation and creates communities of discourse.

\section{LITERATURE AND DISCUSSION}

Early adopters are knowledge community developers and community of discourse moderators. According to Menaker (2011), early adopters suffer from the high impact of marketing and are very aware of organizational communication from technology companies. Enterprises that understand this dynamic must identify early adopters as consumer targets. Messages must be specifically tailored to the early adopter audience. Some of the barriers to early adoption are product function as seen in the usage (TIVO), value (ZUNE), and risk (FLO TV). The second barrier deals with psychological hurdles and deals with message marketing, message tailoring, and knowledge creation. Image is a barrier that does not go away over time and one that only occurs with early adopters as opposed to majority factions. When explicit communication about the product's function and culture was not provided to the early adopter audience, messaging and knowledge cannot become tacit and create the necessary community of discourse around the product.

Derek Sivers discusses this concept of "first followers" at his TEDtalk delivered in February 2010. This talk is titled, "How to start a movement." Sivers states in his conclusion, "If you really care about starting a movement, have the courage to follow and show others how to follow. And when you find a lone nut doing something great, have the guts to be the first one to stand up and join in." In this Sivers lends credibility to a movement if it can gain that first follower. A first follower will signal to other followers that it is advisable to grasp on to an idea and to participate. Therefore, true leadership resides with the person who an enterprise can get to first grasp and own their idea. Advertising and marketing are a critical tool in explicitly communicating the idea to be grasped on to by the consumers.

A critical issue for marketers and academics alike should be examining how enterprises equip early adopters with the proper information in the proper format to breach the adoption gap. How do enterprises equip their brand leaders with knowledge that will be converted and conveyed in a credible way to attract the first followers? Explicit knowledge must bind a community together in the form of an idea, action, or product symbol. This information must then be turned tacit to bind a greater community to create a trend that will move the idea to greater acceptance through continually attracting new members. New members must be intrigued by an idea or unspoken/verbal aspect to a product. In marketing this is represented by the ellipsis (...) (Johnson, 2008), a representation of what is unsaid or non-explicitly known.

By creating targeted and very explicit messaging to early adopters the image and psychological barrier is immediately addressed. This messaging needs to be created intentionally and tested to ensure the encoding of the proper meaning. Explicit knowledge ensures that the early adopters are not left to figure out the identity of the product for themselves, lowering the early adopter tax or the cost to the consumer of buying technology that will be upgraded sometime soon leading the early adopter's purchase to become obsolete before its time. This happens as newer versions of products are release as upgrades to the original. An enterprise that fails to make these considerations risks misinterpretation of identity, use, or value, extending the adoption gap. 


\section{Issues in Information Systems \\ Volume 15, Issue I, pp. 118-122, 2014}

Everett Rogers shows how early adopters with little history of communication from the enterprise have a lower tax, but early adopters with a high history of communication have a higher tax. This risk is created by the potential for and improved version 2.0 being introduced in the foreseeable future. Risk can be mitigated through careful explicit communication to early adopters about current products on true innovation and development, reducing the doubt of functionality and risk of the tax trade occurs. This slows the cycle of consumers waiting for the next best thing and refocuses them on the current benefits through complete, explicit, and early introduction. Give the message to the early adopters to mold and craft to ensure success and niche tacit knowledge communities develop.

When looking at the adoption curve it must be understood that this model applies to new products or new ideas. Coston (2009) shows that marketers should focus on early adopters. As such, at introduction there is little shared knowledge about said product, service, or idea. With little information shared among any communal audience of introduction, an enterprise must be very explicit the initial communication of purpose, use, or product specifications.

Marketing messaging must be explicit and occur through proper channels in order for an intended early adopter audience to grasp any messaging. Assuming tacit information or using the marketing ellipsis in the early adopter stage risks introducing noise to the introduction process. Coston shows that early adopters rely far more on social networks for knowledge gathering than on sales people. Early adopters help turn the explicit information gathered in media and research, created by the enterprise into tacit knowledge through social media sharing and negotiation with early majority followers. Through the very careful crafting of this initial message and information through the proper channels, the enterprise sets the stage for the future understanding of the idea or product. Like a roller coaster, the height of the first drop dictates the speed and intensity of the rest of the ride. The enterprise controls the speed and intensity of adoption and knowledge creation around their product through the height that is built by the initial investment in explicit information provided to early adopters.

Early adopters will take this explicit information and create a shared knowledge base of how this product or service should be interpreted and considered. This knowledge base is created in the form of tacit knowledge. An example of this is that we know that Apple Inc. in the early 00's was very cool and niche, however, we would be hard pressed to understand why. That information has been encoded in tacit knowledge generated from the explicit information provided to the early adopters of the Apple family of products.

\section{PRACTICAL APPLICATION}

In the case of the iPod, Thomas Kuhn defines this normal science as, "predicated on the assumption that the scientific community knows what the world is like." (1996, pg. 5) In this sense we will be taking the perspective that the scientific community developed the iPod technology in an effort to satiate a cultural desire to make the listening experience more individualized and less materialistic. The paradigm shift here is that music has become the property of individualistic listening. The paradigm of the sharing and public use of music has move to ownership and an individual ritual. The scientific community took note of the cultural move to more mobility, convenience, and the technology bubble. To this end, they looked to create a device that allowed the portability of media without the need for extraneous material. The scientific community enhanced the shift to this mobility with the development of the iPod.

Gustavus Stadler discusses the meaning of the move to a digital technology in his 2010 article, Breaking Sound Barriers. "It is worth reminding ourselves, especially having embraced a constructionist view of technology and sound itself, that the various phenomena that construct them nevertheless bear specific traits, patterns of use, and symbolic resonances, even as they are never fully defined by them." Stadler claims that the most prominent of these concepts is that of "liberation." This quote nicely shows this technology development as a normal science in reference to a constructionist view in that there was a base of personal music, science noted a culture shift, and the iPod was constructed to enhance the users experience and fill a coming tech gap. The iPod allowed people to feel freer because they now had less cumbersome "material." They were now free to roam anywhere on earth and have their "life's soundtrack" resonating in their ears.

Apple took this individualization to a psychological level in their early advertisements. The first advertisements consisted of a silhouetted body, dancing on our screen with earbuds in and iPod in hand. At no point does this being interact or share their music. Apple was defining the "new cool" and this cool was a form of solitary elitism. They 


\section{Issues in Information Systems \\ Volume 15, Issue I, pp. 118-122, 2014}

were saying that if you can have this solo experience, you are cool and part of an elite sect of humanity. Apple continued this advertising campaign for years until the technology had become so prevalent that the message was no longer relevant. They had created a culture of I and Me. There was no way to stand out against the culture because the culture did not care that you stood out. Each person was concerned with their world and their soundtrack more than they cared what others were doing. But this was not the end of the dematerialization and individualism paradigm shift.

This individualism brought on by the iPod can be seen culminating in its name. The "i" in iPod is seen as standing for individual. Here we are getting into some semiotics but this lower case "i" in today's culture is a symbol. It stands for Apple, individual, luxury, and elite, among many other concepts. It rejects proper English. It defines Apple's products as something different that do not have to follow the rules. These " $\mathrm{i}$ " products are for those who live by their own rules and they do it alone. This is a meaning that has been cultivated by Apple and their line of "i" products that have evolved from the iPod and iMac. The "i" revolution is the definition of the paradigm shift that the iPod technology defined. It put the " $i$ " in individual and then provided a line of technology that allowed the user to be an individual anywhere and everywhere.

Johnson, F. states, "When presenting technographic discourse elements, the advertiser provides publically understood discourse templates for the consumer to personally navigate..." (2008, p. 158). In the practical case of the iPod, and Apple products in general, the "i" becomes the template for consumer discourse. The "i" is adopted by early investors, given the meaning of "individualism" by the early majority, and consumed en mass by the late majority. This "i" template provided an explicit meaning for early adopters: $\mathrm{i}$ for (i)ndividuality, (i)ndividualism, and (i)nnovative. This did not become tacit until the late majority adoption of the " $\mathrm{i}$ " discourse and integration into other cultural elements beyond Apple. Johnson once again summarizes, "Once these words are in the standard dictionaries, we know they have made it past the fad stage and have likely passed into broader usage" (p.156). This can be seen if one goes to a search engine and precedes any work with the " $i$ " and no space. The viewer will realize that essentially any work in the English language has been combined with this " $i$ " to tacitly mean individual and innovative product solutions.

\section{CONCLUSIONS}

Apple's "i" revolution (iRevolution) provides a great example of how knowledge management can be used to influence the early adopter gap in technology. By explicitly using a symbol and echoing the connotative meanings, "i" gave the early majority a reason to adopt. These meanings became encoded in cultural elements at which time the "i" shared various tacit meanings that could be attached to any number of products and developments. The "i" became a cultural discourse in technology that bridged a gap to a multi-billion dollar empire.

The strategic recommendation generated from this paper is for enterprises to be very clear and strategic in their communication to their audiences. Clearly identify early adopters. Communicate technological specifications, usage, and expected results to this audience. As this product is adopted and proliferated by this audience, follow this curve and support this adoption with communication that supports the developing community of discourse. Create an identity and a sphere that these consumers can engage and own. At this point technical specifications and usage is proliferated by the emerging experts and a culture will develop. This progression is documented as a planned progression from an explicit cultural template to a tacit understanding. A culture emerges that creates communities of understanding which draw new consumers in, facilitating a bridge in the adoption gap.

This article has explored an idea to be researched as to how industries can understand and plan their communication and knowledge transfer process with consumers as products move along this curve. A hypothesis is presented to be tested as to how the adoption gap can be bridged through the management of knowledge in the product lifecycle.

\section{REFERENCES}

Bohlen, J., Beal, G. (1957). The Diffusion Process, [Special Report No. 18]. Agriculture Extension Service, Iowa State College, 1: 56-77.

Bull, Michael (2006, March). Iconic Designs: The Apple iPod. Third International Workshop on Mobile Music Technology. Conducted at University of Sussex, Brighton, UK. 2-3 March 2006. 


\section{Issues in Information Systems \\ Volume 15, Issue I, pp. 118-122, 2014}

DeFrange Coston, R.L. (2009). The influence of the social network: A phenomenological study of early adopter consumers. (Doctoral dissertation) Retrieved from ProQuest Dissertations and Theses. Dissertation/thesis number 3411116

Glasser, Mark (2006). Media Shift, [definition of iPod]. Retrieved September 1, 2011, from http://www.pbs.org/mediashift/2006/01/glossary.html

Gross, Neal C. (1942) The diffusion of a culture trait in two Iowa townships. M.S. Thesis, Iowa State College, Ames.

Johnson, F. (2008). Imaging in advertising: Verbal and visual codes of commerce. New York, NY: Routledge.

Kuhn, Thomas S. (1996). The Structure of Scientific Revolutions. Chicago, IL. University of Chicago Press.

Maguadda, Paolo (2011). When materiality 'bites back': Digital music consumption practices in the age of dematerialization. Journal of Consumer Culture. 11(1). 16-35. Retrieved from http://joc.sagepub.com/content/11/1/15

Menaker, E. (2011). See it want it buy it: The changing face of the early adopter in high technology and the tech industry's targeted public relations campaigns. (Order No. 1497000, University of Southern California). ProQuest Dissertations and Theses, , 84-n/a. Retrieved from http://search.proquest.com/docview/884953956?accountid=28365. (884953956).

Princeton.edu, WordNet Search. [Definition of iPod] Retrieved on September 1, 2011 from http://wordnetweb.princeton.edu/perl/webwn?s=ipod

Ryan, Bryce, and Neal C. Gross (1943) "The diffusion of hybrid seed corn in two Iowa communities." Rural Sociology 8: 15-24. RS(E)

Stadler, Gustavus (2010, Spring). Breaking Sound Barriers. Social Text 101. 28(1). 1-12 Text 101. 28(1). 1-12. 